\title{
Vitamin D and Systemic Lupus Erythematosus: Bones, Muscles, and Joints
}

\author{
Nancy E. Lane
}

Published online: 29 April 2010

(C) The Author(s) 2010. This article is published with open access at Springerlink.com

\begin{abstract}
Vitamin D3, or cholecalciferol, is the naturally occurring form of vitamin D that is converted in the skin and hydroxylated in the liver and kidney to the active form found in humans. The main role for vitamin $\mathrm{D}$ is calcium homeostasis, and low levels of vitamin D result in lower gastrointestinal absorption of calcium. Vitamin D is also critical for mineralization of bone tissue, muscle function, and coordination. Recent studies have found prevention of bone mass loss and reduction in falls and fractures in patients supplemented with vitamin D. A high percentage of systemic lupus erythematosus patients are reported to have insufficient or deficient levels of vitamin D. This paper reviews the biology of vitamin $\mathrm{D}$, its role in calcium homeostasis, and how it contributes to the maintenance of bone, muscle, and joint function in older adults and individuals with systemic lupus erythematosus.
\end{abstract}

Keywords Vitamin D · Systemic lupus erythematosus . Bone and muscle function

\section{Introduction}

Vitamin D3, or cholecalciferol, is the naturally occurring form of the vitamin and is also the active form found in humans. In the skin, under the influence of UV light, 7dehydroxycholesterol is photoconverted to previtamin D3, or cholecalciferol. The previtamin D3, bound to a vitamin D-binding protein, is transported to the liver, where it is

\footnotetext{
N. E. Lane $(\square)$

Aging Center, Medicine and Rheumatology,

University of California at Davis School of Medicine,

4800 2nd Avenue, Suite 2600,

Sacramento, CA 95817, USA

e-mail: nelane@ucdavis.edu
}

hydroxylated to $25(\mathrm{OH}) \mathrm{D} 3$. In the kidneys, $25(\mathrm{OH}) \mathrm{D} 3$ is further metabolized to $1,25(\mathrm{OH}) \mathrm{D} 3$, the biologically active form of vitamin $\mathrm{D}$. The other form of vitamin $\mathrm{D}$, vitamin $\mathrm{D} 2$, or ergocalciferol, is found in plants and is much less potent than vitamin $\mathrm{D} 3$. It is also biologically inert prior to conversion in the liver and kidney to active 1,25 vitamin D3. $1,25(\mathrm{OH}) \mathrm{D} 3$ is nearly 1000 times more potent than the precursor of vitamin D2 or vitamin D3. The major source of vitamin $\mathrm{D}$ is sun exposure; thus, active vitamin $\mathrm{D}$ in the body can be affected by the season and the duration of direct exposure to sunlight and can be inhibited by sunscreen use and increased skin pigmentation.

In contrast to other vitamins, dietary intake is usually a minor source of vitamin D and provides only about $100 \mathrm{IU} / \mathrm{d}$. Vitamin D is rarely found in foods other than eggs, fatty fish, and supplemented dairy products. It can be supplied as a component in combination vitamins or by individual supplements that have become available [1].

\section{Mechanism of Action}

Vitamin D plays a critical role in calcium homeostasis. Maintenance of calcium levels in the body is organized in a balanced system, with vitamin D acting to produce enough gastrointestinal absorption of calcium to satisfy calcium demand and bone turnover. Low levels of vitamin D result in the calcium reserves in bone being depleted in an attempt to correct for the reduced calcium that will be absorbed from the gut. When calcium absorption by bone is reduced and vitamin D status is sufficient, absorption of dietary calcium should be about $30 \%$ to $40 \%$. As vitamin D levels fall, absorption of dietary calcium declines to about $10 \%$ to $15 \%$ [2]. The reduction in intestinal calcium absorption associated with low levels of vitamin D triggers the release 
of parathyroid hormone (PTH), which stimulates the absorption of calcium through augmentation of the production of $1,25(\mathrm{OH})_{2} \mathrm{D}[2,3]$. PTH also mediates the mobilization of calcium from bone by stimulating bone resorption, which results in a reduction in bone mineral density. Chronic elevations of PTH from vitamin D deficiency are associated with increased cortical bone resorption and porosity.

The relationship between vitamin D status and calcium absorption was recently studied in two small, randomized, crossover studies of postmenopausal women. Study participants received commercially available calcium supplements providing about $500 \mathrm{mg}$ of calcium and $200 \mathrm{IU}$ of vitamin D per day. The participants were predosed with 800 IU of 25 $(\mathrm{OH}) \mathrm{D}$ on alternate days for an average of 3 weeks prior to calcium absorption measurements as a way to restore adequate vitamin D levels rapidly [4]. Compared with women who received no $25(\mathrm{OH}) \mathrm{D}$ treatment, those who did undergo this treatment demonstrated a $3.5 \%$ higher $(P<0.002)$ serum calcium concentration prior to calcium supplement ingestion, a $16.5 \%$ lower serum PTH concentration, and a $65 \%$ greater increase in calcium absorption fraction.

\section{Vitamin D and Muscle Function}

During the past 10 to 20 years, many case reports have documented that in both young and old individuals, prolonged vitamin $\mathrm{D}$ deficiency can be associated with severe muscle weakness and disability and has been found to improve within several weeks of vitamin D supplementation $[5,6]$. The findings from a population-based US survey of 4100 ambulatory adults 60 years of age and older suggest an association between vitamin D status and lower extremity function [7]. Lower extremity function in study participants was assessed using an eight-foot walking-speed test, and serum $25(\mathrm{OH}) \mathrm{D}$ concentrations were determined by radioimmunoassay. Test performance speed increased as the $25(\mathrm{OH}) \mathrm{D}$ level rose throughout the reference range of the assay of 9.0 to $37.6 \mathrm{ng} / \mathrm{mL}$, with the most significant improvement observed as $25(\mathrm{OH}) \mathrm{D}$ increased from about 10 to $17 \mathrm{ng} / \mathrm{mL}$. Because this study used a cross-sectional design to analyze the data, a causal relationship between vitamin $\mathrm{D}$ concentration and lower extremity function cannot be established.

The vitamin D receptor (VDR) is present in muscle cells, and the number of VDRs on each muscle cell appears to decrease with age [8]. Binding of vitamin D to its receptor results in the activation of several signaling pathways, including calcium uptake into the muscle cell, phosphate transport across the cell membrane, phospholipid metabo-

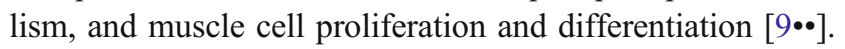
Studies in chick embryo myoblasts demonstrated that short- term treatment with $1,25(\mathrm{OH}) \mathrm{D}$ at roughly physiologic levels increased cell density and fusion of myocytes and had stimulatory effects on their proliferation. However, effects were not seen on the differentiation phase of myocyte development [10]. Some data also support a role

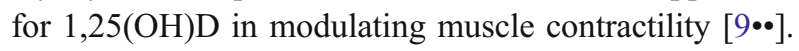

Recent studies in VDR knockout murine models provide additional support for the direct effects of vitamin D and its receptor on skeletal muscle tissue. The VDR-null mouse (lacking the VDR) has a phenotype characterized by reduced bone size, body size, weight, motor coordination, and poor physical performance compared with wild-type mice [11]. Also, metabolic abnormalities associated with lack of the VDR include hypocalcemia, hypophosphatemia, secondary hyperparathyroidism, bone deformity, and muscle fiber changes. These features were more prominent in the VDR-null mouse after weaning and with aging, suggesting a role for the VDR in skeletal development and maturation. However, VDR polymorphisms, which are subtle variations in DNA sequence of the VDR gene, exist that are associated with a range of biologic characteristics, including muscle strength. The Fok1 polymorphism involves a $\mathrm{T} / \mathrm{C}$ transition in exon 2 of the $V D R$ gene [12]. Individuals with the $\mathrm{C}$ allele have a shorter VDR than those with the $\mathrm{T}$ allele, and there is in vitro evidence for enhanced activity of VDR as a transcription factor. Clinically, the C allele has been associated with reduced fat mass and quadriceps strength [12]. More work may be warranted to link signaling through the VDR in muscle with its potential functional consequences.

Muscle biopsies from adults with profound vitamin D deficiency had shown predominant type II fiber atrophy. As type II muscle fibers are the initial fibers to be recruited for balance and coordination, this may explain some of the tendency for increased falls in individuals who are vitamin D deficient. Histologic sections of type II muscle fibers show enlarged interfibrillar spaces and infiltration of fat, fibrosis, and glycogen granules [13, 14].

Two small studies have evaluated vitamin D supplementation and muscle fiber composition. One randomized controlled clinical trial of older adult stroke victims found that $1000 \mathrm{IU}$ of vitamin D2 over a 2-year period increased percentage and mean diameter of type II muscle fibers [14]. Furthermore, serum 25(OH)D level was correlated with both the baseline type II muscle fiber diameter and the diameter after 2 years of follow-up.

A few clinical trials have evaluated the combination of calcium and vitamin D to determine whether this kind of supplement might alter the risk of falling in older adults. A double-blind, randomized trial in Switzerland studied the effect of vitamin D and calcium supplementation on the risk of falling among 122 women (mean age, 85.3 years) cared for in long-term geriatric care units before transfer into nursing 
homes. Study participants were randomly assigned to receive $1200 \mathrm{mg} / \mathrm{d}$ of calcium alone or calcium $1200 \mathrm{mg} / \mathrm{d}$ plus $800 \mathrm{IU} / \mathrm{d}$ of vitamin D for 12 weeks. The mean serum 25(OH) D concentration prior to treatment was $12 \mathrm{ng} / \mathrm{mL}$ in both treatment groups. Vitamin D and calcium supplementation accounted for a $49 \%$ reduction in the risk of a fall $(P=0.01)$ after adjusting for 1) age, 2) the number of participants who fell during a 6-week pretreatment period, 3) the number of falls per person during the pretreatment period, 4) baseline serum levels of $25(\mathrm{OH}) \mathrm{D}$ and $1,25(\mathrm{OH})_{2} \mathrm{D}$, and 5) the observation time during treatment. This reduction may be attributable to the significant improvement $(P=0.0094)$ in musculoskeletal function detected in patients who received vitamin $\mathrm{D}$ and calcium. Because of a high number of transfers to nursing homes, the dropout rate in this study was high. All study participants were institutionalized older European women from Switzerland, so the study results may not be generalizable across a more broad population [15]. Bischoff et al. [15] performed a meta-analysis of several small clinical studies that evaluated the effect of vitamin D treatment compared with control groups on the risk of falling and found that vitamin $\mathrm{D}$ replacement favored a reduction in number of falls, with an overall OR of about 0.75 .

\section{Vitamin D and Bone Mass and Fractures}

The most important determinants of the risk of skeletal fracture are low bone mass, microarchitectural deterioration, and a propensity to fall. Adequate vitamin $\mathrm{D}$ is critical for bone formation. Higher levels of $25(\mathrm{OH}) \mathrm{D}$ have been associated with higher bone mineral density at the hip in young and older men and women from the Third National Health and Nutrition Examination Survey at levels up to $36.8 \mathrm{ng} / \mathrm{mL}$ [16], and supplementation of vitamin D in older adults also prevents bone loss [17]. A recent study from the Women's Health Initiative cohort also confirmed that women who had a hip fracture had significantly lower $25(\mathrm{OH}) \mathrm{D}$ values than controls. Also, women in the lowest quartile for $25(\mathrm{OH}) \mathrm{D}$ had a nearly 1.7 -fold higher risk of hip fracture than women in the higher quartile for $25(\mathrm{OH}) \mathrm{D}[18 \bullet]$.

Nutritional vitamin D deficiency causes insufficient mineralization of bone tissue and rickets in growing children and osteomalacia in adults. The active form of vitamin D, $1,25(\mathrm{OH}) \mathrm{D}$, stimulates the absorption of calcium and phosphorus from the gastrointestinal tract, thereby making calcium and phosphorus available for mineralization. In mild vitamin D deficiency, the elevation of serum PTH increases the conversion of $25(\mathrm{OH}) \mathrm{D}$ to $1,25(\mathrm{OH}) \mathrm{D}$ to compensate for the insufficient $25(\mathrm{OH}) \mathrm{D}$ available; however, elevation in PTH increases bone resorption, leading to additional bone loss [19]. Clinical osteomalacia usually is present with severe vitamin $\mathrm{D}$ deficiency at levels of $5 \mathrm{ng} / \mathrm{mL}$ or less. The clinical manifestations of osteomalacia include bone pain, muscular weakness generally of the proximal shoulder and hip girdle, and difficulty walking. If the calcium is also low in patients with osteomalacia, symptoms of low calcium, such as tetany or seizures, may be present. Fractures of the bone may occur because the quality of the bone in osteomalacia with reduced mineralization is more fragile than bone of normal mineral quality. A transiliac bone biopsy after fluorochrome labeling is required to confirm the diagnosis of osteomalacia. The specimens should be stained with Goldner or von Kossa stains for mineralizing surface. The bone histology section has less than 5\% nonmineralized bone matrix or osteoid. However, with osteomalacia, the osteoid surface may be as high as $70 \%$, and bone resorption may be slightly increased due to secondary hyperparathyroidism [19].

\section{Vitamin D as a Treatment to Prevent Osteoporotic Fractures}

A randomized, double-blind trial in the United Kingdom examined the effect of oral vitamin D supplementation on the risk of fracture in 2686 men and women 65 to 85 years of age who were living in the community. Study participants were randomly assigned to receive a single oral dose of 100,000 IU of vitamin D3 or matching placebo every 4 months for 5 years, which is equivalent to a daily dose of about $800 \mathrm{IU}$. The incidence of fracture of the hip, wrist, forearm, or vertebrae was $4.5 \%$ in volunteers assigned to receive vitamin $\mathrm{D}$ and $6.5 \%$ in those given placebo $(P=$ 0.02 ), and the age-adjusted relative risk of fracture at these sites was 33\% lower with vitamin D. To maximize generalizability, exclusion criteria were minimal. However, this approach introduces increased variables that can hamper the interpretability of the findings. The data were ascertained via self-report questionnaire, which could have led to ascertainment errors [20]. In another study, institutionalized older adult women in France were randomly assigned to calcium and vitamin $\mathrm{D}, 800 \mathrm{IU} / \mathrm{d}$, or placebo for 18 months. Hip and other nonvertebral fracture rates were reduced by nearly $40 \%$ in the treated participants compared with the placebo group [21].

\section{Vitamin D Intake Requirements}

In 1997, the Institute of Medicine of the National Academy of Sciences made recommendations for vitamin D intake. The recommendations are as follows:

- Adults up to 50 years of age: supplementation with $5 \mu \mathrm{g} / \mathrm{d}$, or $200 \mathrm{IU}$ 
- Adults 51 to 70 years of age: $10 \mu \mathrm{g} / \mathrm{d}$, or $400 \mathrm{IU}$

- Adults older than 71 years of age: $15 \mu \mathrm{g} / \mathrm{d}$, or $600 \mathrm{IU}$.

These recommendations are based on the amount of vitamin D that is needed to maximally suppress PTH (184) secretion [22], but there is no consensus, as some investigators advocate that the $25(\mathrm{OH})_{2} \mathrm{D}$ level needed to maximally suppress PTH is 30 to $44 \mathrm{ng} / \mathrm{mL}$ [23]. The current recommendation for vitamin $\mathrm{D}$ supplementation of $600 \mathrm{IU}$ for men and women older than 71 years of age is not sufficient to bring the level of $25(\mathrm{OH}) \mathrm{D}$ to 30 to $32 \mathrm{ng} / \mathrm{mL}$, which is the level needed to lower fracture risk. Given the need to reach $25(\mathrm{OH}) \mathrm{D}$ levels of at least $30 \mathrm{ng} / \mathrm{mL}$, it is recommended that the supplementation be enough to achieve this level. The National Academy of Sciences has recommended that the safe upper limit of 25 $(\mathrm{OH}) \mathrm{D}$ be $50 \mu \mathrm{g} / \mathrm{d}$, or $2000 \mathrm{IU}$.

Vitamin D is available in two forms: ergocalciferol, or D2 (the plant form), and cholecalciferol, or D3 (animal origin). Studies have found that vitamin D3 increases serum 25(OH)D more effectively than vitamin D2 [24]. Therefore, vitamin D3 is the preferred form for clinical use.

In summary, vitamin $\mathrm{D}$ is important for the maintenance and function of the musculoskeletal system. As they age, or due to nutritional deficiencies, many men and women need supplementation to meet the daily requirements and maintain normal serum concentrations. The general consensus is that a $25(\mathrm{OH}) \mathrm{D}$ level of $20 \mathrm{ng} / \mathrm{mL}$, or $75 \mathrm{nM}$ or higher, along with adequate calcium intake is needed to lower fracture risk, maintain well-mineralized bone matrix tissue, and maintain adequate muscle strength and function. Most older adults will need to be supplemented with 800 to $1000 \mathrm{IU} / \mathrm{d}$ of vitamin D3 to reach this level.

\section{Treatment Options for Patients With Vitamin D Deficiency}

Physicians and health care providers have several options for treating vitamin D insufficiency or deficiency. A loading dose of vitamin D can rapidly increase $25(\mathrm{OH}) \mathrm{D}$ to the normal range, and in the clinic, we frequently prescribe 50,000 IU of vitamin D once per week for about 8 weeks [23]. In our experience, the vitamin D levels often decline without maintenance therapy, so we recommend vitamin D doses of 400 to $1000 \mathrm{IU} / \mathrm{d}$ or to continue the 50,000 IU of vitamin D2 every 2 to 4 weeks. It is important to evaluate patients with recurrent vitamin D deficiency for evidence of fat malabsorption, celiac disease, or renal disease, as these individuals may need treatment of their underlying medical condition and possibly a higher maintenance dose of vitamin D to maintain normal, sufficient levels.
Vitamin D and Systemic Lupus Erythematosus Patients

Several recently published reports have indicated that a high percentage of individuals with systemic lupus erythematosus have insufficient or deficient levels of $25(\mathrm{OH}) \mathrm{D}$ $[25,26]$. In practice, rheumatologists may be treating these patients with vitamin D2 or D3 supplements to increase serum levels of $25(\mathrm{OH}) \mathrm{D}$ to greater than $30 \mathrm{ng} / \mathrm{mL}$. Although several anecdotal reports note that raising the serum concentrations to more than $30 \mathrm{ng} / \mathrm{mL}$ is associated with improvement in musculoskeletal disease symptoms, a formal clinical study has not yet been completed, although the Immune Tolerance Network is conducting a study to evaluate the effect of raising $25(\mathrm{OH}) \mathrm{D}$ levels on parameters of autoimmunity and systemic lupus erythematosus activity. Until the results of this trial are published, this author suggests that replacement of $25(\mathrm{OH}) \mathrm{D}$ to levels greater than $32 \mathrm{ng} / \mathrm{mL}$ should maximize the absorption of calcium from the gastrointestinal tract with reasonable suppression of serum PTH levels.

\section{Conclusions}

Vitamin D is critical for bone and muscle function. At this time, serum levels of $25(\mathrm{OH}) \mathrm{D}$ should be maintained at $32 \mathrm{ng} / \mathrm{mL}$ until further research determines whether higher serum levels improve outcomes.

Acknowledgment This work was supported by National Institutes of Health grants R01 AR043052 and K24 AR-048841 to Dr. Lane.

Disclosure No potential conflict of interest relevant to this article was reported.

Open Access This article is distributed under the terms of the Creative Commons Attribution Noncommercial License which permits any noncommercial use, distribution, and reproduction in any medium, provided the original author(s) and source are credited.

\section{References}

Papers of particular interest, published recently, have been highlighted as:

- Of importance

•- Of major importance

1. Dusso AS, Brown AJ: Mechanism of vitamin D action and its regulation. Am J Kidney Dis 1998, 32(2 Suppl 2):S13-S24.

2. Malabanan AO, Holick MF: Vitamin D and bone health in postmenopausal women. J Womens Health (Larchmt) 2003, 12:151-156.

3. Lips P: Vitamin D deficiency and secondary hyperparathyroidism in the elderly: consequences for bone loss and fractures and therapeutic implications. Endocr Rev 2001, 22:477-501. 
4. Heaney RP, Dowell MS, Hale CA, Bendich A: Calcium absorption varies within the reference range for serum 25hydroxyvitamin D. J Am Coll Nutr 2003, 22:142-146.

5. Mingrone G, Greco AV, Castagneto M, Gasbarrini G: A woman who left her wheelchair. Lancet 1999, 353:806.

6. Prabhala A, Garg R, Dandona P: Severe myopathy associated with vitamin D deficiency in western New York. Arch Intern Med 2000, 24:160:1199-1203

7. Bischoff-Ferrari HA, Dietrich T, Orav EJ, et al.: Higher 25hydroxyvitamin D concentrations are associated with better lowerextremity function in both active and inactive persons aged $>$ or $=$ 60 y. Am J Clin Nutr 2004, 80:752-758.

8. Bischoff HA, Borchers M, Gudat F, et al.: In situ detection of 1,25-dihydroxyvitamin D3 receptor in human skeletal muscle tissue. Histochem J 2001, 33:19-24.

9. - Ceglia L: Vitamin D and skeletal muscle tissue and function. Mol Aspects Med 2008, 29:407-414. This is an outstanding review of the basic and translational science of the VDR in muscle tissue and muscle function

10. Drittanti L, deBoland AR, Boland R: Modulation of DNA synthesis in cultured muscle cells by 1,25dihydroxyvitamin D-3. Biochim Biophys Acta 1989, 1014:112-119.

11. Kalueff AV, Lou YR, Laaksi I, Tuohimaa P: Impaired motor performance in mice lacking neurosensory vitamin D receptors. Brain Res Bull 2004, 64:25-29.

12. Hopkinson NS, Li KW, Kehoe A, et al.: Vitamin D receptor genotypes influence quadriceps strength in chronic obstructive pulmonary disease. Am J Clin Nutr 2008, 87:385-390.

13. Yoshikawa S, Nakamura T, Tanabe H, Imamura T: Osteomalacic myopathy. Endocrinol Jpn 1979, 26(Suppl):65-72

14. Sato Y, Iwamoto J, Kanoko T, Satoh K: Low-dose vitamin D prevents muscular atrophy and reduces falls and hip fractures in women after stroke. A randomized controlled trial. Cerebrovasc Dis 2005, 20:187-192.

15. Bischoff HA, Stähelin HB, Dick W, et al.: Effects of vitamin D and calcium supplementation on falls: a randomized controlled trials. J Bone Miner Res 2003, 18:343-351.

16. Bischoff-Ferrari H, Dietrich T, Orav EJ, Dawson-Hughes B: Positive association between 25-hydroxyvitamin D levels and bone mineral density; a population based study of younger and older adults. Am J Med 2004, 116:634-639.

17. Ooms ME, Roos JC, Bezemer PD, et al.: Prevention of bone loss by vitamin $\mathrm{D}$ supplementation in elderly women: a randomized double-blind trial. J Clin Endocrinol Metab 1995, 80:10521058.

18. • Cauley JA, Lacroix AZ, Wu L, et al.: Serum 25 hydroxyvitamin D concentrations and risk for hip fractures. Ann Intern Med 2008, 149:242-250. This was an important study that determined in a large cohort of older women that low levels of serum $25(\mathrm{OH}) \mathrm{D}$ significantly increased the risk of hip fractures. Although these data do not determine whether the effect is through muscle or bone, the result is valid and supports the need to maintain $25(\mathrm{OH})$ $D$ at levels at or above $32 \mathrm{ng} / \mathrm{mL}$

19. Lips P, van Schoor NM, Bravenboer N: Vitamin D related disorders. In Primer of Metabolic Bone Diseases, edn 7. Edited by Rosen C. Washington, DC: American Society of Bone and Mineral Research; 2009:329-334

20. Trivedi D, Doll R, Khaw KT: Effect of four monthly oral vitamin D3 (cholecalciferol) supplementation on fractures and mortality in men and women living in the community: randomized double blind controlled trial. BMJ 2003, 326:469.

21. Chapuy MC, Arlot ME, Duboeuf F, et al.: Vitamin D3 and calcium to prevent hip fractures in elderly women. N Engl J Med 1992, 327:1627-1642.

22. Dawson-Hughes B: Calcium and vitamin D. In Primer of Metabolic Bone Diseases, edn 7. Edited by Rosen C. Washington, DC: American Society of Bone and Mineral Research; 2009:231233

23. Dawson-Hughes B, Heaney RP, Holick MK, et al.: Estimates of optimal vitamin D status. Osteoporos Int 2005, 16:713-716.

24. Armas LA, Hollis BW, Heaney RP: Vitamin D2 is much less effective than vitamin D3 in humans. J Clin Endocrinol Metab 2004, 89:5387-5391.

25. Toloza SM, Cole DE, Gladman DD, et al.: Vitamin D insufficiency in a large female SLE cohort. Lupus 2010, 19:13-19.

26. Borba VZ, Vieira JG, Kasamatsu T, et al.: Vitamin D deficiency in patients with active systemic lupus erythematous. Osteoporos Int 2009, 20:427-433. 